\title{
Modeling of the processes of increasing foreign economic potential of the microeconomic system
}

\author{
D. Vasylkivskyi ${ }^{1}$, O. Yaremenko $^{1}$, M. Levchenko ${ }^{1}$ \\ ${ }^{1}$ International Economic Relations Department, Khmelnytskyi National University
}

\section{Article Info}

Received Dec 18, 2018

Keyword:
Foreign economic potential
Fuzzy modeling
Information system
Microeconomic system
Strategy

\begin{abstract}
The enterprise as an economic system at the micro level is characterized by uncertainty in situations when making decisions, a large number of input indicators, as well as the presence of a decision maker of information that is poorly formalized and cannot be taken into account when applying only quantitative methods. The uncertainty of the system leads to an increased risk of ineffective decisions, which may result in negative economic, technical and social consequences. The research considers the main structural elements of the strategy of developing the foreign economic potential of microeconomic systems. On the basis of calculations, the clear meaning of the indicators that are included in the groups defining the basic elements of the external economic potential is obtained. The algorithm of forming the strategy of development of the foreign economic potential of the enterprise is presented in the framework of the general approach to the organization of the process of increasing the foreign economic potential of microeconomic systems on the basis of a unified information system. As a result of the formation of a mechanism for increasing the foreign economic potential of microeconomic systems, a strategy was developed that was based on substantiation of the direction of development of foreign economic potential in accordance with the level of influence of external factors, using the method of fuzzy modeling and modeling the process of organizational interaction.
\end{abstract}

\section{Corresponding Author:}

D. Vasylkivskyi,

International Economic Relations Department,

Khmelnytskyi National University,

Instytutska 11, Khmelnytskyi, 29016, Ukraine.

Email: vasilkivsky@gmail.com

\section{Introduction}

The peculiarity of the market environment in which the microeconomic systems operate is extreme instability and often unpredictability of the development of events in the economic, political, social and other spheres. The scientific sources emphasize the role of the external environment to assess the possibility of increasing the foreign economic potential of microeconomic systems [1]. In the framework of the assessment of the competitive status, methods are used to determine the place of the factors of the environmental factors of positive and negative orientation [2]. However, the competitive status of microeconomic systems is a measure that shows the competitiveness of foreign economic potential and besides the direct assessment of the size of foreign economic potential, it is necessary to determine the direction of its development. However, the success of any process is to determine and predict the impact of the maximum number of factors that either contribute or counteract this development. One of the most important tasks in defining the strategy of development of foreign economic potential within the framework of the economic mechanism is the assessment of the impact of environmental factors [3]. Moreover, in this regard, the effectiveness of the mechanism of increase is directly dependent on the ability to timely identify, classify and formulate measures that reduce the risk of 
achieving strategic goals. The general provisions of this theory were formulated in the works of such scientists as L.A. Zadeh and A. Kofman [4, 5], where the possibilities of using linguistic variables for the solution of applied problems were substantiated. There was also a substantiated difference from the existing methods of approximation, which are widely used in statistics. Later, this theory has become quite widespread in management models (M. Dziedzic, S. Zadro zny, J. Kacprzyk) [6], in particular for expert systems, and situational approach in management (M.J. Mohammadizadeh, A.R. Karbassi) [7], in the management of nonstationary systems of electric drives (H.H. Fang, H.S. Lee, S.N. Hwang, C.C. Chung) [8], and during the evaluation and formation of structures Business Communications (A. Awasthi, S.S. Chauhan, H. Omrani) [9]. The unpredictability of the external environment sometimes dictates the conditions for modeling the reaction in response. The factors of the external macro environment on the part of the microeconomic systems cannot be controlled while operating the macro factors are the most important in the majority of cases. The level of control within the framework of development should serve as a criterion for assessing the effectiveness of the entire organizational and economic mechanism for improving the foreign economic potential.

\section{Materials and methods}

\subsection{Economic and mathematical modeling}

During the study, the following methods were used: economic-statistical, systemic and comparative analysis for the analysis of the economic state of microeconomic systems, with the purpose of identifying priority areas for increasing foreign economic potential; economic and mathematical modeling, formalization, programming - to determine the methodology for the development of the strategy of the foreign economic potential of microeconomic systems, which provides the possibility of conducting diagnostics and substantiation of development priorities within the framework of the fuzzy modeling method. That provides the possibility of establishing fuzzy boundaries of the basic parameters of development and determines the interaction of elements of foreign economic potential in the process of implementing the strategy.

The intuitive simplicity of fuzzy logic as a methodology for solving problems ensures its successful use in the embedded control and analysis of information systems. Unlike traditional mathematics, fuzzy logic offers a completely different level of thinking, which is largely based on the creative process, which in turn is perhaps the main precondition for developing an adequate strategy for a modern enterprise [10].

\subsection{Fuzzy modeling methods}

Fuzzy numbers obtained because of "not quite accurate measurements" are largely similar to the distribution of probability theory, but are free from the inherent defects of the last: a small number of suitable for analysis of distribution functions, the need for their forced normalization, the difficulty of substantiating the adequacy of mathematical abstraction for describing behavior actual quantities. Compared with the probabilistic method, the fuzzy method allows to sharply reducing the volume of computations, which, in turn, leads to an increase in the speed of fuzzy systems [11].

For a static estimation of foreign economic potential, the formula with a partial case for a set of fuzzy numbers is used, since in the transformation of indicators, the variables Rijz (partial indicator characterizing a specific element of foreign economic potential) are transformed into a phase-size and elements of foreign economic potential and the entire foreign economic potential of the microeconomic system.

Let us denote the essence of this method in the framework of the given task, for which we illustrate the logic and peculiarities of the calculations. Thus, during the transfer of an ordinary number, the whole set of fuzzy numbers acquires the image of the fuzzy-number. The solution to this type of task belongs to a class of triangular fuzzy numbers were:

a - center;

CL - the value of the fuzzy on the left;

$\mathrm{cR}$ is the fuzzy value to the right.

The triangular number $\mathrm{N}$ given in this way corresponds to the fuzzy set $\mathrm{A}(\mathrm{N})$ whose membership function is defined on the set of negative real numbers and has the following form [12]: 


$$
F_{A(N)}(Y)=\left\{\begin{array}{c}
0,0<y<a-c_{L} \\
\frac{y-a-c_{L}}{c_{R}}, a-c_{L}<y<a \\
\frac{a+c_{R}-y}{c_{R}}, a<y<a+c_{R} \\
0, a+c_{R}<y
\end{array}\right.
$$

This feature function has the form of a triangle with vertices at coordinate points $\left(a-c_{L}, 0\right) ;(a, 1) ;\left(a+c_{R}, 0\right)$.

The result of any arithmetic operations, in which at least one fuzzy number participated, will be a phase number. In other words, it will be the result of an arithmetic operation, in which at least one fuzzy-number participated. When added to a normal number, the values of fuzziness left and right for the fuzzy-numbers remain unchanged, only the center of the number changes. For this, in the unchanged form, the initial operation of the addition is performed. In the process of adding two fuzzy numbers, respectively, the centers of the fuzzy-numbers, their sizes of fuzziness to the left, their sizes of fuzziness to the right. Let us represent the addition operation for two fuzzy numbers:

And

$$
A=(x ; y ; z)=(x ; x-\Delta x ; x+\Delta x) \text {; }
$$

$$
B=(k ; s ; \mathrm{g})=(k ; k-\Delta k ; k+\Delta k) .
$$

The result of this operation will also be a phase number $C=(d ; e ; f)$, where:

$$
d=x+k, e=y+s=x-\Delta x+k-\Delta k, f=z+q=x+\Delta x+k+\Delta k .
$$

To perform the multiplication operation between a phase number and an ordinary number, we sequentially multiply the three components of the phase-integer: the center, the magnitude of the deviation to the left, the magnitude of the deviation to the right. Similarly, we present the operation of the product of two fuzzy numbers $\mathrm{A}$ and $\mathrm{B}$, which will result in a fuzzy number $D=A \cdot B=(n ; m ; v)$, where:

$$
\begin{gathered}
\begin{array}{c}
n=x \cdot k ; \\
m=y \cdot s=\frac{x(k-\Delta k)+k(x-\Delta x)}{2}
\end{array}=x \cdot k-\frac{x \cdot \Delta k+k \cdot \Delta x}{2} \\
v=z \cdot g=\frac{x(k+\Delta k)+k(x+\Delta x)}{2}=x \cdot k+\frac{x \cdot \Delta k+k \cdot \Delta x}{2} .
\end{gathered}
$$

In the formula for calculating the foreign economic potential of a microeconomic system at a certain stage of the life cycle, two main operations - addition and multiplication, which, with the transition to a set of fuzzy numbers, will be performed for phase numbers, are used.

\section{Results and discussion}

The result of the implementation of the strategic development plan of the foreign economic potential of microeconomic systems and its separate components is to increase the competitive status, and, therefore, to preserve the long-term competitiveness of the enterprise. The effectiveness of the mechanism of foreign economic potential is largely determined by the thoughtfulness of the used estimation technologies, methods of analysis and forecasting.

\subsection{Strategic orientation of the enterprise}

The purpose of evaluating the foreign economic potential of the microeconomic system is to indicate the next strategic orientation of the enterprise, and the research of the potential of the market is to characterize the general market opportunities of enterprises of one branch affiliation. Therefore, the external economic potential of the microeconomic system can be divided into four categories: the functioning, strategic, problem and synergistic potential of the enterprise. Potential of functioning is the core of foreign economic potential, 
through which the main activities are carried out. Without an appropriate structure of the functioning potential, the enterprise is not able to fulfill its mission [13].

In addition to the potential for an operation, an enterprise often has a range of potential means that may or may not be of strategic interest, namely the importance of their extraordinary role in the implementation of specific strategies. At the same time, the benefits in the current period of such potential means are rather conditional.

The problem of potential (or excess) can be considered as a partial case of strategic planning, that is, having no opportunity to realize the strategic potential, the company is somehow obliged to have additional costs for its maintenance. For example, it has significant production capacities, which are used only by $30 \%$. Without a strategy or a set of strategies aimed at expanding production, this potential advantage is a source of additional costs. A similar example relates to individual elements of staff potential. For example, employees who have received additional education or improved their qualifications also become a part of the problem potential in the absence of career growth and incentive programs [14].

Thus, the above is entirely consistent with the theory of strategic management, which states that unused and unrealized opportunities become sources of additional costs and sometimes threats to the enterprise. In addition, finally, some potential means are synergistic in the sense that they themselves are not capable of giving strategically obvious advantages, but in combination with other means can have a significant effect in order to promote the more efficient use of other potentials.

\subsection{Theory of fuzzy logic}

One of the essential features of forming a strategy for developing foreign economic potential is to predict the level of development of its individual elements. Speaking about development strategies, it should be noted that the time somewhat blurs contours of the usual values of the presented system of indicators, turning them into fuzzy numbers. That is, in particular, about the size of Rijz. Hence, all operations related to the estimation and prediction of the level of development of individual elements of foreign economic potential, obey the laws of the theory of fuzzy logic.

As flaws in fuzzy logic, one can distinguish the lack of a standardized method for constructing fuzzy systems, the impossibility of mathematical analysis by using the existing methods, and that the use of fuzzy approach compared with probabilistic does not lead to an increase in the accuracy of the calculations.

However, not all of these disadvantages, in our opinion, are significant enough, for example, the principle of fuzziness is laid down in the basic principles of strategy formation, the violation of which results in a lack of strategic maneuver in the implementation of a long-term development strategy.

\subsection{Strategy for the development of the foreign economic potential}

The application of the method of fuzzy logic within the framework of the task of forming a strategy for the development of the foreign economic potential of the microeconomic system receives, in this way, a certain sequence of operations. Based on calculations, the indicators of the groups that determine the basic elements of the foreign economic potential, and, consequently, the actual foreign economic potential of the microeconomic system, are clear. The preliminary stage, which operates with clear values, is necessary for the formation of a predictable strategy (a number of strategies) for the development of foreign economic potential, since the primary values of Rijz indicators are the source information for more accurate determination of the values of the elements of the potential, as well as its approximate boundaries, after the strategy is implemented with the correct accuracy of the parameters. The new values of the Rijz indicators are determined by the set of fuzzy numbers, by which the degree of approximation of this value is also determined. In turn, based on unclear indicators of the indicators, the fuzzy value of the main elements of the foreign economic potential of the microeconomic system is formed [15].

Recently, scientists and practitioners have paid special attention to the methodology of strategic planning. Regarding the strategy of development of foreign economic potential strategic plans should be based on the analysis of the forecast of the situation on the micro, macro and mezzo levels, as well as the actual capabilities of the enterprise. The earlier analysis of the external environment, the aggressiveness of the external environment, functional demand, as well as the existing mechanism of the management and development, operating in enterprises, allows you to target the majority of investigated enterprises on the strategy of development of individual elements of foreign economic potential. However, when forming a development plan, it is necessary to take into account the mutual influence and significance of the elements, in other words, 
to focus on the priority in development. Table 1 presents the matrix of the interaction of elements of foreign economic potential in the process of implementation of the development strategy.

This matrix shows the nature of the mutual influence of the main elements of foreign economic potential.

Table 1. Matrix of interactions of elements of foreign economic potential in the process of realization of development strategy

\begin{tabular}{|c|c|c|c|c|}
\hline \multirow{2}{*}{ Elements } & \multicolumn{4}{|c|}{ Element of Foreign Economic Capacity (EC) } \\
\hline & Personnel & Industrial & Financial & Scientific and technical \\
\hline Personnel & & $\begin{array}{l}\text { Improve } \\
\text { ergonomics and } \\
\text { anthropometry of the } \\
\text { workplace. Safety of } \\
\text { labor. Automation of } \\
\text { production processes }\end{array}$ & $\begin{array}{l}\text { Improvement of systems } \\
\text { of motivation, financing } \\
\text { of programs of } \\
\text { adaptation, preparation } \\
\text { and advanced training }\end{array}$ & $\begin{array}{l}\text { Improve the use of } \\
\text { existing and further } \\
\text { buildup of the } \\
\text { information base }\end{array}$ \\
\hline Industrial & $\begin{array}{l}\text { Formation of } \\
\text { personnel reserve, } \\
\text { increase of production- } \\
\text { professional } \\
\text { characteristics of } \\
\text { personnel }\end{array}$ & & $\begin{array}{l}\text { Increase in the value of } \\
\text { assets of an enterprise } \\
\text { with an increase } \\
\text { insales volumes. } \\
\text { Financing modernization } \\
\text { programs }\end{array}$ & $\begin{array}{l}\text { Development of a bank } \\
\text { of technological } \\
\text { reserves } \\
\text { and developments } \\
\text { ready to be } \\
\text { involved. Orientation of } \\
\text { development on } \\
\text { ecological } \\
\text { (non-waste) technology }\end{array}$ \\
\hline Financial & $\begin{array}{l}\text { Activity-oriented } \\
\text { orientation. Increasing } \\
\text { Initiative and } \\
\text { Entrepreneurship. Prof } \\
\text { essional development } \\
\text { of specialists }\end{array}$ & $\begin{array}{l}\text { Intensification of } \\
\text { growth of volumes of } \\
\text { production, increase of } \\
\text { its profitability, } \\
\text { programs of economy } \\
\text { of fuel, materials, } \\
\text { energy resources }\end{array}$ & & $\begin{array}{l}\text { Information support for } \\
\text { financial projects, } \\
\text { innovative security } \\
\text { projects }\end{array}$ \\
\hline $\begin{array}{l}\text { Scientific } \\
\text { and } \\
\text { technical }\end{array}$ & $\begin{array}{l}\text { The development of } \\
\text { scientific awareness } \\
\text { personnel, increase of } \\
\text { information } \\
\text { literacy, scientific } \\
\text { and creative activity }\end{array}$ & $\begin{array}{l}\text { The combination of } \\
\text { design } \\
\text { and technological } \\
\text { preparation of } \\
\text { production. Improveme } \\
\text { nt of the state of } \\
\text { production assets }\end{array}$ & $\begin{array}{l}\text { Increase in the value of } \\
\text { intangible } \\
\text { assets. Increasing } \\
\text { financing of energy } \\
\text { saving and hi- } \\
\text { tech programs }\end{array}$ & Scientific and technical \\
\hline
\end{tabular}

\subsection{Model of the process of diagnostics of foreign economic potential}

In Fig. 1 the model of the process of diagnostics of foreign economic potential and formation of a development strategy based on the method of fuzzy modeling is presented.

As experience shows, with a reasonable professional approach to the implementation of the information system, you can create a tool for more effective management, and for a range of tasks, this is not only an effective but also often the only way. It is obvious that with consistent automation, especially with a small area, significantly reduces the burden on staff and minimizes the inevitable organizational and psychological problems of implementation.

It should, however, be borne in mind that the process of harmonizing priority of the development parameters is an integral part of the development mechanism. A similar process is carried out by a group of experts who establish and agree, in addition to the composition of the parameters, the acceptable values of their deviations in such way as to ensure, as a result, the level of development of foreign economic potential.

The calculations are carried out with the help of the standardized software Microsoft Access "Expert system for assessing the direction of development of the external economic potential of the microeconomic system." 


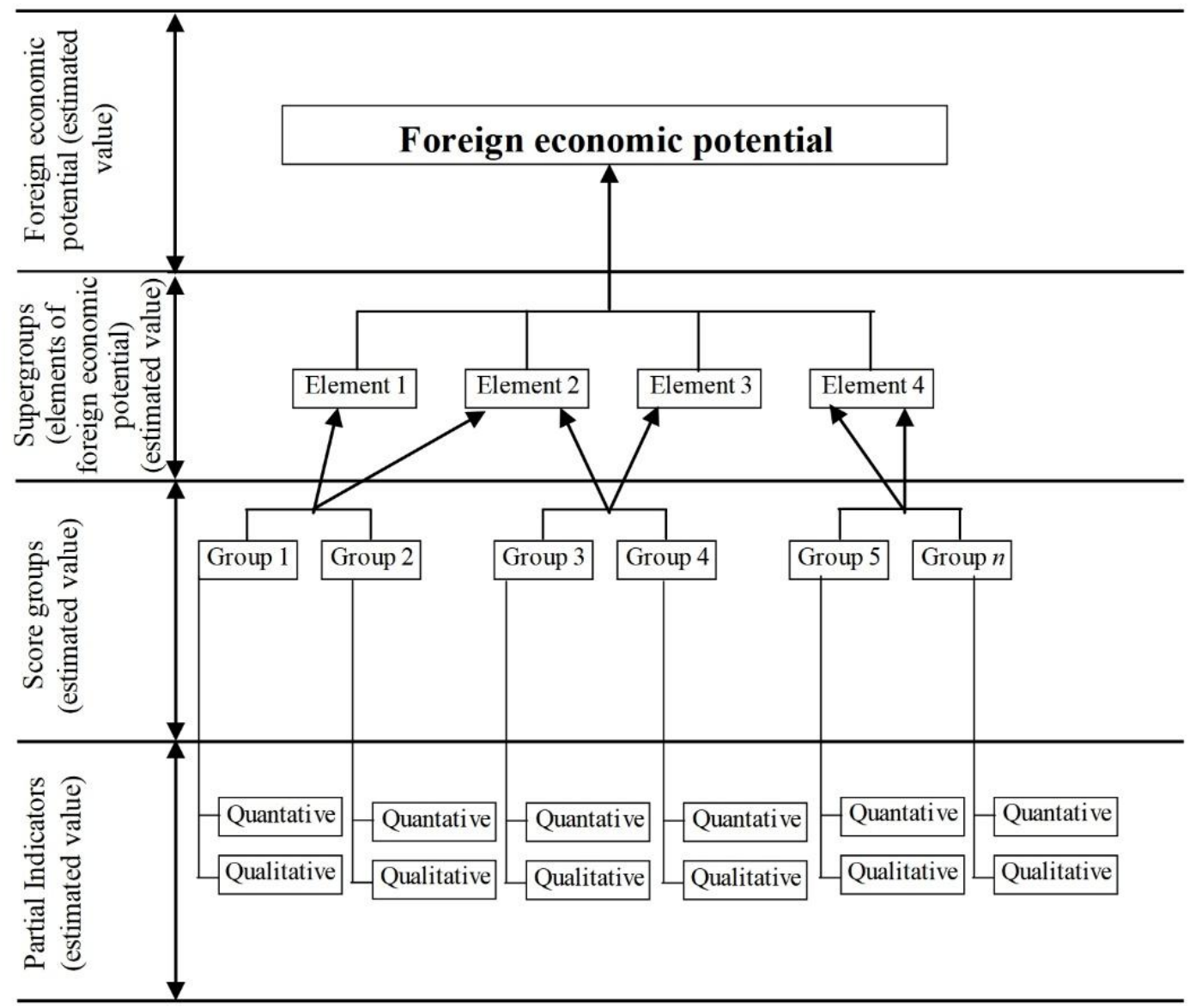

Figure 1. Model of the process of diagnostics of foreign economic potential and formation of a development strategy based on the method of fuzzy modeling (stage 1)

In the first stage, we conduct an analysis of the existing state of foreign economic potential for the indicators that we have selected. Thus, an understanding of the existing level of external economic potential and constituent elements is formed.

At the second stage (Fig. 2), in accordance with the method of fuzzy modeling, at each of the levels of diagnostics (level of partial indicators, groups of indicators, external economic potential and its elements) two deviations are established, in addition to the predicted level of the development.

Thus, the strategy of development of foreign economic potential using fuzzy modeling methods involves realization of the following directions: personnel development; use and expansion of internal capabilities of the enterprise; modernization of the existing production potential of microeconomic systems on the basis of available opportunities; introduction of innovative achievements in the production-technological base of the enterprise; use of industry opportunities; promotion of modernization of the industrial potential of the enterprise by sector resources; implementation of sectorial and national development programs.

In other words, in the beginning - due to the organizational and managerial efforts of the enterprise itself, the use of existing opportunities is ensured, in the future - modernization of the enterprise to increase its competitiveness. The next stage is the implementation of the state policy aimed at strengthening the competitive position of the company in the national and foreign markets.

Based on the developed elements of the mechanism for improving the external economic potential, and based on the conclusions drawn, it is quite evident that the effectiveness of the formation and implementation of plans and programs of strategic development is impossible without the involvement of the outside experts. In particular, as already noted - an external consultant. The solution to this problem is greatly simplified with the introduction of information technology. 


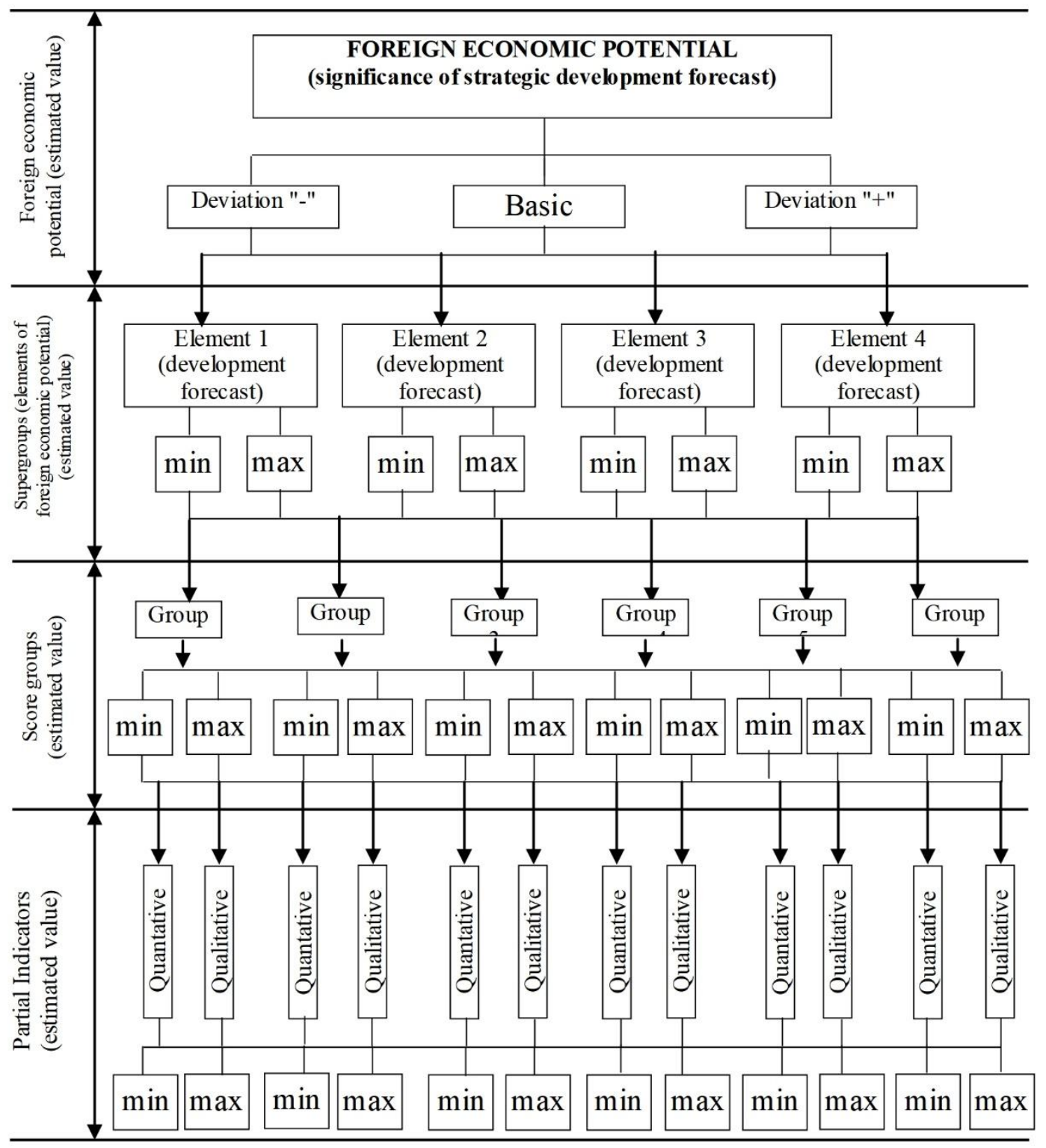

Figure 2. Model of the process of diagnostics of foreign economic potential and the formation of a development strategy based on fuzzy simulation method (step 2)

The value adopted in the framework of the development strategy characterizes the most favorable situation; the lower threshold for the effective implementation of the strategic development decisions determines an unfavorable but acceptable and predictable development situation.

The main task of automating the adoption of complex managerial decisions is to ensure information interaction in the process of forming a strategy for the development of the plan. Moreover, such interaction should cover not only the services and units of the enterprise itself but also ensure the timely receipt of information from external sources. Requirements for the information system providing such interaction should be completely concrete, among the main ones one can propose the following:

1. Adaptability. Due to the fact that Ukrainian practice does not have enough experience in the field of development and implementation of information systems in enterprises, and the largest developers are foreign companies, the system should be adapted to the features of Ukrainian legislation and settlement systems (their changes), and the specifics of a particular enterprise.

2. Reliable information protection. Since most of the investigated companies have a sufficient amount of classified information, they need the protocols of restricted access, the reliability of the storage of information, which at the same time should not reduce the quality of interaction.

3. The ability for remote access. When implementing an enterprise with a complex organizational structure, 
implementation of remote access is necessary in order for the information to be used by all structural divisions of the organization.

4. Consolidation of information at the enterprise level in the framework of individual tasks and periods.

5. The speed and reliability of information flow for all participants involved in developing a development strategy - working for a particular enterprise and beyond.

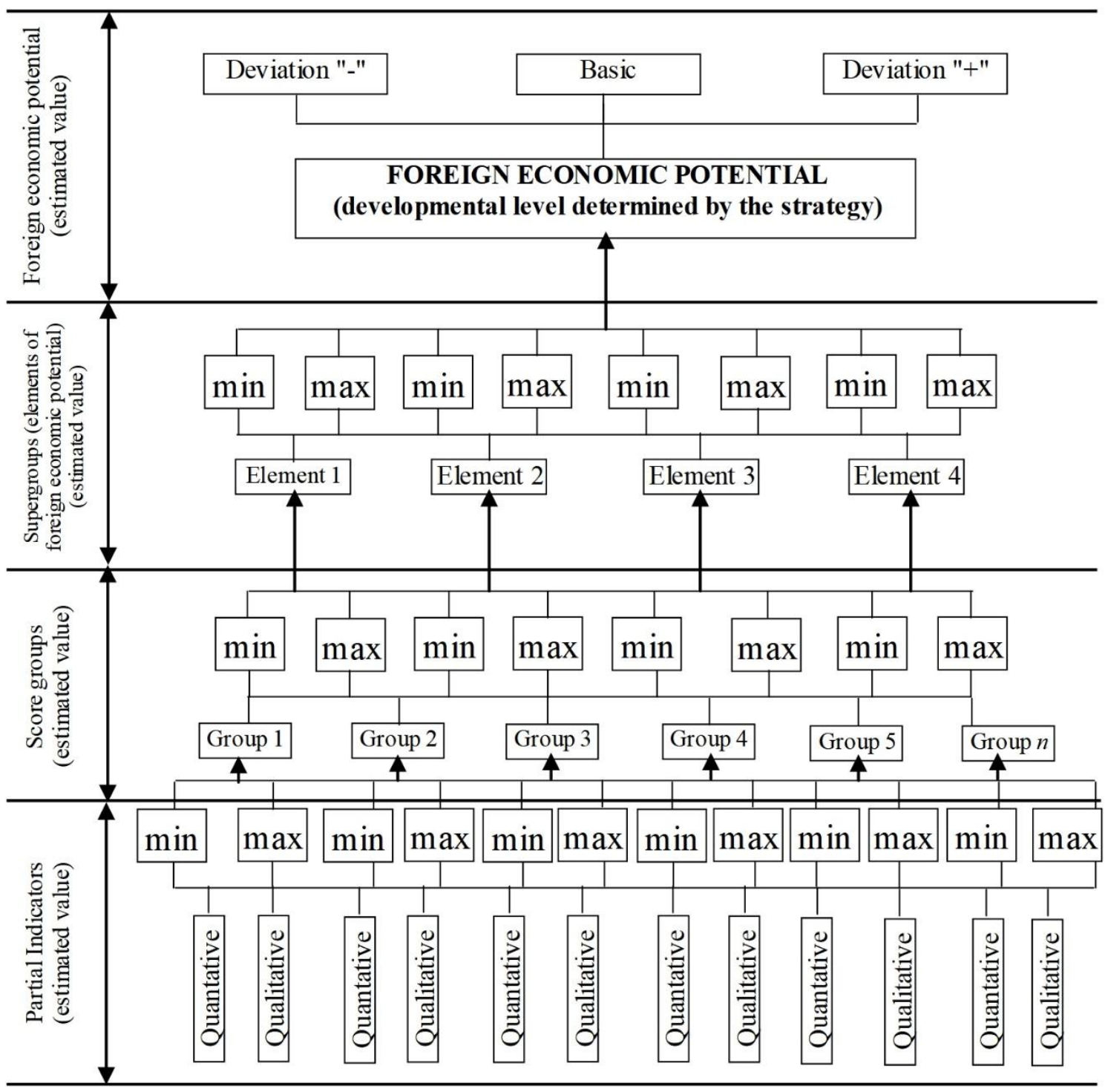

Figure 3. Model of the process of diagnostics of foreign economic potential and the formation of a development strategy based on fuzzy simulation method (step 3)

Actually, the development strategy is designed for three years. In the absence of the possibility of reaching the lower threshold of development (or deviation with the sign "-"), there is a need to revise the strategy.

According to the logic of the proposed method, as well as the priority of the strategic direction of development, the enterprises in today's conditions are able to implement a strategy of passive response to external conditions, and have only limited opportunities for development; therefore, it is necessary to allocate the third stage of the model of development strategy development.

Stage 3 (Fig. 3) involves the allocation of key (priority) groups at all levels, capable of providing the optimal level of development of the entire foreign economic potential.

At the same time, the important quality of such a system is that the system has the ability to grow from top to bottom, when it primarily does not automate the activities of the executors, and the level of preparation and structured presentation of information for the management of higher and middle levels, which in principle meets the requirements for the formation of a development strategy the external economic potential of the 
microeconomic system (Fig. 4, a, b).

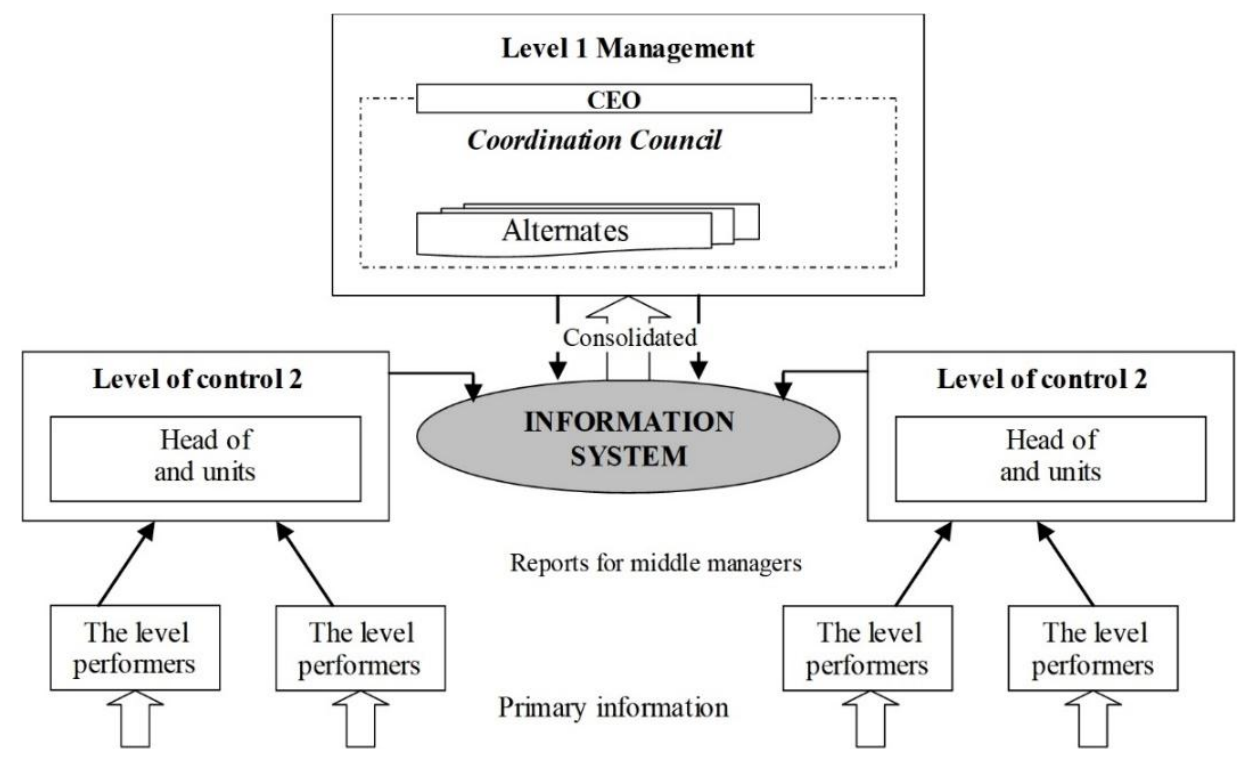

a) stage 1: automation of the upper levels of management

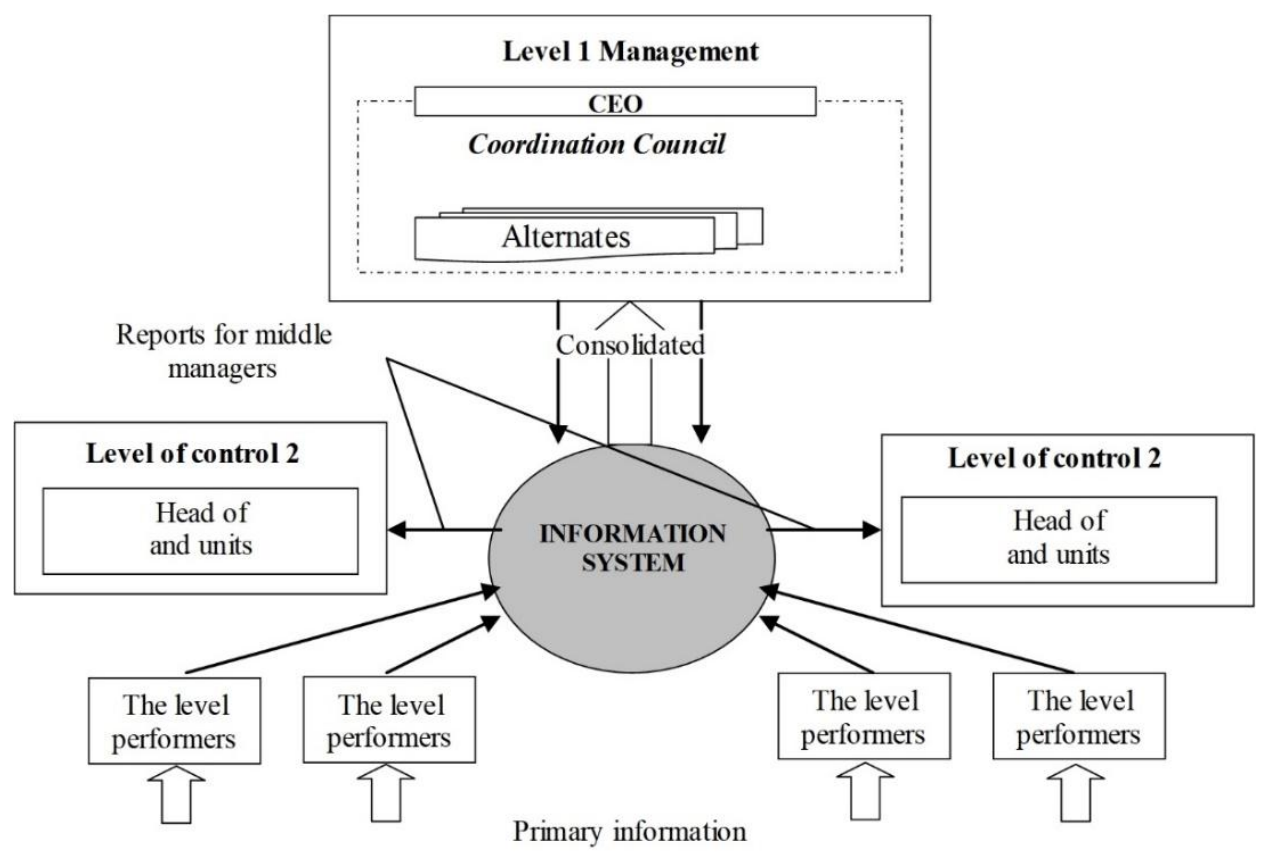

b) Stage 2: the creation of a single information space

Figure 5. Implementation of the information system (stages 1 and 2)

\subsection{Algorithm for forming a strategy for the development of an FEP}

The listed methods are more aimed at assessing the position of the enterprise in the external environment. Assessing the state of the internal environment is most appropriate on the basis of the analysis of economic activity, which is a systematic, complex study, measurement and generalization of the influence of factors on the results of the enterprise through the processing of special methods of system indicators of the plan, accounting, reporting and other sources of information in order to improve the efficiency of production . Fig. 5 presents the algorithm for forming the strategy of development of the foreign economic potential of the microeconomic system. 


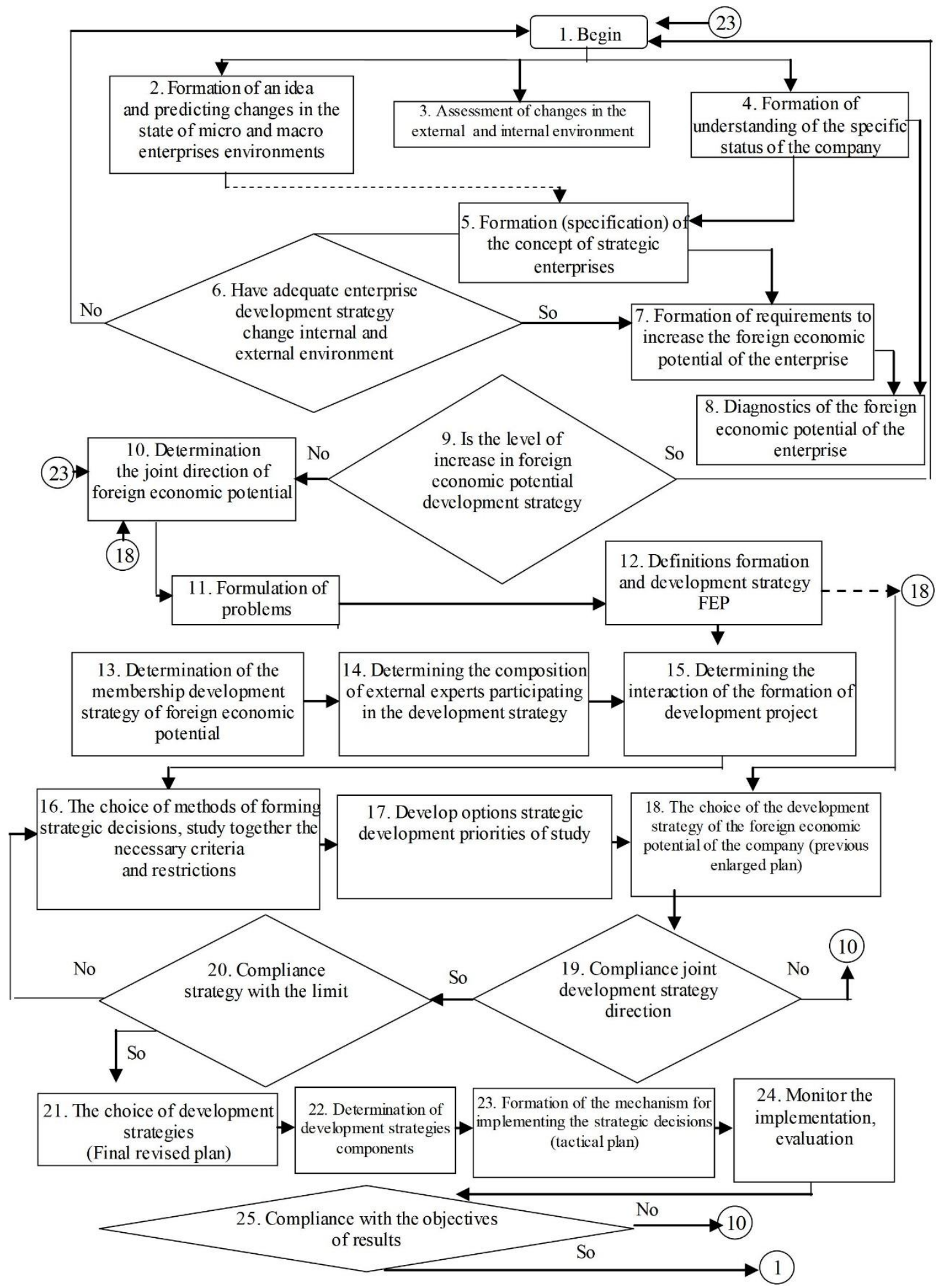

Figure 5. Algorithm for forming a strategy for the development of an FEP (consolidated approach) Given that the economic activity includes separate subsystems, we distinguish the appropriate types of analysis, combined in the analysis of economic activity, namely analysis:

- techno-economic. Its main functions are assigned to the technical services of the enterprise (chief engineer, chief technologist, etc.). The content is the study of the interaction of technical and economic processes and their impact on the economic performance of the enterprise;

- financial and economic - focuses on the financial results of the company's activities: implementation of the financial plan, the efficiency of using its own and loan capital;

- audit (accounting) - is an expert diagnosis of financial "health" of the enterprise; 
- economic-statistical - is used to study mass social phenomena at different levels of management: enterprises, industries, regions;

- marketing - is used to study the external environment of the functioning of the enterprise, markets for raw materials and sales of finished products.

\section{Conclusion}

Therefore, the strategy of development of foreign economic potential by using the fuzzy modeling methods involves realization of the following directions: personnel development; use and expansion of internal capabilities of the enterprise; modernization of the existing production potential of the enterprise on the basis of available opportunities; introduction of innovative achievements in the production-technological base of the enterprise; use of industry opportunities; promotion of the modernization of production potential; implementation of sectoral and national development programs.

The proposed method of determining the direction of strategic development allows, depending on the degree of destructive influence of micro-, macro- and mesor-equilibrium, to develop attributive characteristics of development, namely, a vector, trajectory, and direction that defines the general (most appropriate) level of potential development, which is expressed in active, passive or compensation model of development. The methodology of formation of the strategy of foreign economic potential of the system, provides the possibility of establishing fuzzy boundaries of the basic parameters of development and determines the interaction of elements of foreign economic potential in the process of strategy implementation.

\section{Acknowledgement}

Authors are grateful to the Department of International Economic Relations of Khmelnytskyi National University for their assistances in analyzing foreign economic potential of enterprises.

\section{Abbreviations and Acronyms \\ FEP Foreign Economic Potential \\ CEO Chief Executive Officer}

\section{REFERENCES}

1. D.M. Vasylkivskyi. "Formation of strategic decisions on managing the process of improving the economic potential of the enterprise", Actual probl. of the econ., vol. 4, pp. 162-167, 2012.

2. N. Zaredar, M. Kheirkhah Zarkesh, S.A. Jozi, A. Ghadirpour. "Investigation of fuzzy as well as Boolean logics application in land evaluation (case study: TALEGHAN basin-Iran)", International Conference on Environmental and Agriculture Engineering (ICEAE), Japan, pp. 354-357, 2010.

3. M. Peneder. "Entrepreneurial competition and industrial location", Edward Elgar Publish. Ltd, pp. 47-51, 2001.

4. L.A. Zadeh. "The concept of a linguistic variable and its application to making approximate decisions", Mir, pp. 297-324, 1975.

5. A. Kofman. "Introduction to the theory of fuzzy sets", Radio and communic., pp. 347-368, 1982.

6. M. Dziedzic, S. Zadro zny, J. Kacprzyk. "Bipolar linguistic sum-maries: a novel fuzzy querying driven approach”, Joint IFSA World Congr. and NAFIPS Ann. Meet., pp. 1279-1284, 2013.

7. M.J. Mohammadizadeh, A.R. Karbassi, G.R. Nabi Bidhendi, M. Abbaspour. "Integrated environmental management model of air pollution control by hybrid model of DPSIR and FAHP", Global J. Environ. Sci. Manage., vol. 2, pp. 381-388, 2016.

8. H.H. Fang, H.S. Lee, S.N. Hwang, C.C. Chung. "A slacks-based measure of super-efficiency in data envelopment analysis: An alternative approach", Omega, vol. 41, pp. 731-734, 2013.

9. A. Awasthi, S.S. Chauhan, H. Omrani. "Application of fuzzy TOPSIS in evaluating sustainable transportation systems", Expert Syst. Appl., vol. 38, pp. 12270-12280, 2011.

10. W.B. Liu, D.Q. Zhang, W. Meng, X.X. Li, F. Xu. "A study of DEA models without explicit inputs", Omega, vol. 39, pp. 472-480, 2011.

11. M.E. David, F.R. David. "The quantitative strategic planning matrix (QSPM) applied to retail computer store", Coastal Business J., vol. 8, pp. 42- 52, 2009.

12. K. Zare, J.Mehri-Tekmeh, S. Karimi. "A SWOT framework for analyzing the electricity supply chain using an integrated AHP methodology combined with fuzzy-Topsis", Int. Strategy Manage. Rev., vol. 3, pp. 66-80, 2015. 
13. M.O. Levchenko. "Methods and technologies of innovative product output on the market", Herald of Khmeln. Nation. Univ., vol. 3, pp. 39-42, 2013.

14. O.F. Yaremenko. "Scientific approaches to the concept of the economic system and its development", Herald of Khmeln. Nation. Univ., vol. 6, pp. 111-116, 2016.

15. V. Babenko, O. Nazarenko, I. Nazarenko, O. Mandych. "Aspects of program control over technological innovations with consideration of risks", East.-Europ. J. of Enterp. Tech., vol. 3/4, pp. 6-14, 2018.

16. V. Babenko, N. Chebanova, N. Ryzhikova, S. Rudenko, N. Birchenko. "Research into the process of multi-level management of enterprise production activities with taking risks into consideration", East.-Europ. J. of Enterp. Tech., vol. 3, pp. 4-12, 2018.

17. A.B. Krutik, O.G. Markushevich. "Mechanism of enterprise management in the conditions of a free economy", Politekhnika, pp. 49-87, 1992.

18. N.G. Malyshev, L.S. Bershtein, A.V. Bozhenyuk. "Fuzzy models for expert systems in CAD", Energoatomizdat, pp. 302-312, 1991.

19. A. N. Melikhov, L.C. Bernstein, S.Ya. Korovin. "Fuzzy Situational Advisory Systems", Nauka, pp. 46-57, 1990.

20. S.A. Orlovskiy. "Decision making problems with fuzzy source information", Nauka, pp. 258-266, 1981.

21. R. Yager. "Fuzzy sets and the theory of possibilities. Recent achievements", Radio $i$ svyaz, pp. 301-309, 1986.

22. Serdar Ulubeyli, Aynur Kazaz, Volkan Arslan. "A Structured Selection Process for Small and Medium Enterprises in Construction Industry: Case of International Projects", Periodicals of Engineering and Natural Sciences, pp. 263-270, 2017.

23. Sathish Kumar. P, Arun Raaza. "Study and Analysis of Intrusion Detection System Using Random Forest and Linear Regression", Periodicals of Engineering and Natural Sciences, pp. 197-200, 2018.

24. Victor Vladareanu, Luige Vladareanu, Radu Ioan Munteanu, Lucian Capitanu, Emilian M. Dobrescu, Mihai Rădulescu, Vlad Alexandru Grosu. "Adaptive Neural Network Fuzzy Inference System for HFC Processes", Periodicals of Engineering and Natural Sciences, pp. 311-317, 2019. 